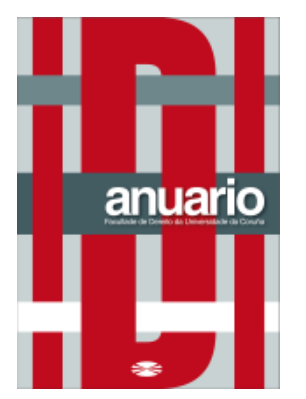

Anuario da Facultade de Dereito da Universidade da Coruña

Vol. 24 (2020), pp. 64-82

ISSNe: 2530-6324 || ISSN: 1138-039X

DOI: https://doi.org/10.17979/afdudc.2020.24.0.7460

\title{
SMEND Y KELSEN, ESTADO COMO INTEGRACIÓN Y PROBLEMAS ACTUALES
}

\section{SMEND AND KELSEN, STATE AS INTEGRATION AND CURRENT PROBLEMS}

\author{
DANIEL JOVE VILLARES \\ Investigador predoctoral FPU \\ Universidade da Coruña \\ https://orcid.org/0000-0002-1164-7796
}

Recibido: 25/07/2020

Aceptado: 24/09/2020

Resumen: Este artículo analiza la controversia suscitada entre Hans Kelsen y Rudolf Smend en torno a la teoría del Estado como integración enunciada por éste último. Para ello se exponen las características fundamentales de ambas teorías, prestando especial atención al concepto de Estado, noción que resultará fundamental para comprenderlas. El concepto de integración y su importancia en la conformación de los estados es el eje central de un artículo en el que, junto al análisis de obras de los dos iuspublicistas, apunta la importancia de lo simbólico en la configuración de un modelo de país capaz de aglutinar las diferentes realidades que en él conviven.

Palabras Clave: Teoría del Estado, Integración, Bandera, Monarquía, Cuestión territorial.

\begin{abstract}
This article analyzes the controversy between Hans Kelsen and Rudolf Smend on the theory of the state as integration, enunciated by the aforementioned Rudolf Smend. In order to do so, it outlines the fundamental characteristics of both theories, paying special attention to the concept of the State, a notion that will prove fundamental to understanding them. The concept of integration and its importance in the formation of states is the central topic of an article in which, together with the analysis of the works of the two authors, points out the importance of the symbolic in the configuration of a model of country capable of bringing together the different realities that coexist in it.
\end{abstract}


Keywords: Theory of the State, Integration, Flag, Monarchy, The territorial question.

Sumario: I. PROBLEMAS VIEJOS EN ODRES NUEVOS. II. LA REPÚBLICA DE WEIMAR COMO TELÓN DE FONDO. III. EL PUNTO DE PARTIDA DE LA CONTROVERSIA. LAS OBRAS PROTAGONISTAS DEL CONFLICTO Y LA CUESTIÓN METODOLÓGICA. 1. La teoría y la réplica. 2. La cuestión metodológica IV. LAS TEORÍAS DEL ESTADO EN BELIGERANCIA. ESPECIAL ATENCIÓN A LA TEORÍA DEL ESTADO COMO INTEGRACIÓN. 1. La teoría del Estado de Kelsen. A. La identidad entre Estado y Derecho. B. Consecuencias para el concepto de Constitución. 2. El Estado como integración. A. Características generales de la teoría de Smend. B. La integración personal. C. Integración funcional o procesal. D. La integración material. E. Consecuencias de la teoría de la integración para el concepto de Constitución. 3. Las críticas de Kelsen a la teoría de la integración. V. CONCLUSIONES DE LA CONTROVERSIA Y REFLEXIONES SOBRE LA REALIDAD ACTUAL. BIBLIOGRAFÍA.

\section{PROBLEMAS VIEJOS EN ODRES NUEVOS}

Los símbolos lo son no solo por lo que son en esencia, sino por lo que representan; por los sentimientos que hacen reverberar en el imaginario colectivo. La adhesión que generan, las pasiones u odios que despiertan, les hacen transcender y les sitúan en una posición diferente de la que pudiera esperarse de su realidad. A veces, esa función simbólica acaba teniendo translación positiva, incluso constitucional (v. gr. art. 56.1 de la Constitución española ${ }^{1}$ ). Ese reconocimiento normativo, además de ser la plasmación de una realidad concreta, sirve de refuerzo y refrendo, al revestir al valor simbólico con la certeza, seguridad y garantías de lo jurídico.

Cuando la fortaleza de algo depende de aquello que representa, asienta sus pies sobre un terreno potencialmente inestable. Naturalmente, la estabilidad y permanencia de los símbolos dependerá de la base sobre la que se sustenten, algunos tendrán los pies de barro y otros se asentarán sobre la falla de una placa tectónica. En el primer caso, no será estable, sobre todo al principio; en el segundo, puede permanecer durante años tranquilo, pero siempre habrá el riesgo de que una sacudida se lo lleve por delante. En definitiva, la fortaleza de los símbolos vendrá determinada por su propia capacidad para mantener (o reforzar) los intangibles que los han dotado de tal condición.

Si las características, valores y méritos que les confirieron dicha posición dejan atribuírseles, si en el inconsciente colectivo dejan de identificarse con aquello que representan, o pasan a provocar afectos diferentes de aquellos que le situaron en una posición merecedora de protección y reconocimiento, los símbolos pasan a estar en peligro,

1 Artículo 56.1 Constitución española, “El Rey es el Jefe del Estado, símbolo de su unidad y permanencia” 
bien de desaparición, bien de convertirse, cual expresidente de gobierno, en "un jarrón chino en un apartamento pequeño ${ }^{2}$.

Los símbolos y los mitos han existido desde que existe vida en sociedad. En los últimos tiempos, en España, algunos de esos símbolos, v. gr. bandera o la monarquía, han visto mermadas su fuerza aglutinante (con intensidades muy distintas y por motivos diferentes). En el caso de la bandera, la identificación - ¿acaso apropiación? - de este símbolo con un modo concreto de entender la vida en común, con una determinada tendencia ideológica, le debilita, al reducir su capacidad de generar adhesión. Al verse arrastrada a la lucha política diaria, acaba generando desafectos, no directamente por ella generados, sino por asociación. En el caso de la monarquía, la pérdida de fuerza adhesiva vendría propiciada, sobre todo, por las mellas que el elemento personal pudiera provocar en la institución (símbolo).

En este artículo se recupera un debate con un siglo de antigüedad que, sin embargo, dista de estar resuelto. Para ello se acudirá a aquellos que mejor formularon los diferentes problemas que en torno a la conformación del estado y su organización política. De este modo, y de la mano de dos de los más grandes iuspublicistas del siglo XX, se analizará la importancia de la integración como elemento conformador del Estado. Para ello se tomará como referencia Constitución y Derecho constitucional de Rudolf Smend y la réplica de Hans Kelsen en El Estado como integración. Una controversia de principio ${ }^{3}$.

\section{LA REPÚBLICA DE WEIMAR COMO TELÓN DE FONDO}

En ocasiones, los escenarios, los paisajes, los contextos son tan relevantes en una obra como los propios personajes y sus acciones. Hay películas, cuadros o novelas en las que el entorno en que se desarrollan las vidas de los protagonistas importa tanto o más que su devenir. Hay paisajes, hechos o períodos históricos que imprimen carácter, que justifican una existencia o que, al menos, la marcan de manera indeleble. La República de Weimar (1918-1933), “el microcosmos cultural del Derecho político continental europeo”4, es uno de esos momentos.

${ }^{2}$ Afortunada metáfora de Felipe González (expresidente del gobierno de España) que, además de para referirse a la delicada posición institucional y política de los expresidentes, sirve para reflejar la realidad de los símbolos caídos en desgracia.

${ }^{3}$ Para el análisis de las obras de Smend y Kelsen se han utilizado las siguientes ediciones traducidas: SMEND, R., Constitución y derecho constitucional, Centro de Estudios Constitucionales, Madrid, 1985 y KELSEN, H., El Estado como integración. Una controversia de principio, ed. Tecnos, Madrid, 1997. No obstante, debe apuntarse que, con motivo del centenario de la Constitución de Weimar, se ha publicado una edición que reúne ambas obras, con un estudio introductorio con las aportaciones de José María Beneyto, Juan Antonio García Amado y Gregorio Robles Morchón, los dos primeros, además, son los traductores de las dos obras que protagonizan el libro. Vid. SMEND, R. y KELSEN, H., La controversia Smend/Kelsen sobre la integración en la Constitución de Weimar: Constitución y Derecho Constitucional versus El Estado como integración, Tecnos, Madrid, 2019.

${ }^{4}$ LUCAS VERDÚ, P. L., La lucha contra el positivismo jurídico en la República de Weimar, Ed. Tecnos, Madrid, 1987, p. 42. 
La República de Weimar ofreció el escenario perfecto para la reflexión y cuestionamiento del papel del Derecho ${ }^{5}$, de la concepción del Estado y de la organización del poder; en definitiva, era el caldo de cultivo perfecto para la reflexión sobre el papel de las constituciones en la organización de la vida en sociedad. La República de Weimar no es solo la forma política adoptada por Alemania tras su derrota en la I Guerra Mundial, es, también, su primera experiencia democrática y, a lo que aquí nos interesa, es la cuna de "un nuevo tipo histórico de constitución -la constitución democrática [...] - y puede ser considerada, por ello, el texto fundacional del constitucionalismo democrático y social del siglo XX”6 . Semejante contexto histórico sirvió, probablemente como ninguna otra época, como acicate y fuente de inspiración para la reflexión y repensado de la ordenación jurídica de la vida en sociedad, de la democracia y, en lo que aquí interesa, de la Teoría del Estado.

Sea porque "la imaginación jurídico-constitucional se agudiza en épocas críticas”7 -probable- sea por una coincidencia cósmica que situó a las personas adecuadas, en el lugar preciso y en el momento oportuno, lo cierto es que, la República de Weimar vio coincidir en el tiempo, y prácticamente en un mismo país, a algunos de los iuspublicistas más relevantes de la historia (v. gr. Heller, Schmitt, Kelsen, o el propio Smend) ${ }^{8}$.

La controversia aquí analizada da buena cuenta de la altura intelectual de los debates acecidos al calor de la Constitución de Weimar -como lo son, también, los debates entre Schmitt y Kelsen ${ }^{9}$-. De este modo, en la formulación de la teoría de integración, Smend se incluye una crítica abierta y directa a los constituyentes de Weimar por no haber incorporado y tomado en consideración elementos integradores, que sí reconoce en la constitución de Bismark, a la que califica de integradora ${ }^{10}$. Del mismo modo, la respuesta formulada por Kelsen, plantea los efectos de dicha teoría no en abstracto, sino desde lo jurídico, desde la plasmación positiva que tenían como referencia, la Constitución de 1919. Como puede constatarse, el escenario, el contexto que la República de Weimar representa, es un actor más a considerar, un factor necesario para comprender, en toda su extensión, la controversia que aquí se tiene ocasión de analizar.

${ }^{5}$ CASQUETE y TAJADURA son los autores de una detallada y bien documentada monografía sobre el contexto histórico, político y jurídico de la Constitución de Weimar, CASQUETE, J. y TAJADURA, J., La Constitución de Weimar: Historia, política y derecho, Centro de Estudios Políticos y Constitucionales, Madrid, 2020.

${ }^{6}$ CASQUETE, J. y TAJADURA, J., La Constitución de Weimar, cit., p. 18.

${ }^{7}$ Cfr. LUCAS VERDÚ, P. L., La lucha contra el positivismo, cit., p. 44. El acierto de este apunte no es menor, en la medida en que tan insignes juristas quizá no hubiesen llevado su producción a tan elevadas cotas si la situación política y jurídica fuera más estable y consolidada.

${ }^{8}$ Si bien debe señalarse que Hans Kelsen era austríaco y Hermann Heller era de origen polaco, ello no fue óbice para que ambos tuvieran un papel significativo en el desarrollo de la Teoría del Estado alemana. Sin embargo, no debe ignorarse el hecho de que no eran alemanes (recuérdese que H. Kelsen es el más ilustre representante de la Escuela de Viena) y eran judíos, lo que acarrearía terribles consecuencias para sus vidas con el ascenso del nacismo.

${ }^{9}$ DE MIGUEL BÁRCENA, J. y TAJADURA TEJADA, J., Kelsen versus Schmitt. Política y derecho en la crisis del constitucionalismo, Guillermo Escolar editor, Madrid, 2018.

10 SMEND, R., Constitución y derecho constitucional, Centro de Estudios Constitucionales, Madrid, 1985, p. 69. 


\section{EL PUNTO DE PARTIDA DE LA CONTROVERSIA. LAS OBRAS PROTAGONISTAS DEL CONFLICTO Y LA CUESTIÓN METODOLÓGICA}

\section{La teoría y la réplica}

Dos no se enfrentan si uno no quiere, pero, cuando la disputa es intelectual, la argumentación sólida, la temática determinante y la exposición clara, bienvenido sea el intercambio de ideas. La polémica entre Kelsen y Smend tiene como origen la publicación, por este último, en 1928, de la obra Verfassung und verfassungsrecht, (Constitución y Derecho constitucional). Con esta obra Smend pretende “dilucidar de entre los diversos intentos de fundamentar filosóficamente las ciencias del espíritu, aquel que pueda resultar más fructífero y útil, para explicitar posteriormente su operatividad en el contexto de las necesidades específicas de la teoría del Estado"11. Para alcanzar dicho objetivo formula quizá sería más exacto decir esboza- su propia teoría. Una teoría material del Estado que ha de poseer "una justificación propia, en cuanto ciencia del espíritu que abarca el ámbito cultural y espiritual de la dinámica estatal" ${ }^{2}$. Sin embargo, Smend, al definir los fundamentos de su teoría del Estado -la teoría de la integración- lo hace planteándola en clara oposición con la Teoría de la Escuela de Viena.

Kelsen recogerá el guante arrojado por Smend y, dos años después, en 1930 responderá con Der Staat als Integration. Eine prinzipielle Auseinandersetzung (El Estado como integración. Una controversia de principio). En esta obra diseccionará, de un modo tan crítico como pormenorizado y preciso, la propuesta de Smend; consciente de que, quizá, su respuesta va más allá de una simple réplica o del mero intercambio de pareceres. Es una enmienda, una contraargumentación minuciosa de cada uno de los elementos que, para Kelsen, resultan disonantes de los postulados de Smend. La envergadura y grado de detalle de su análisis dan fe de ello. La justificación de este proceder obedecería por varios factores:

En primer lugar, por quien es el autor. Que haya realizado un estudio tan completo de la obra de Smend, demuestra un reconocimiento a la talla intelectual de éste, atestigua el respeto que sentía por su figura y su obra, aunque discrepe abiertamente con la doctrina por él formulada ${ }^{13}$. En segundo lugar, por el impacto que la teoría de la integración había tenido y las consecuencias que de ello pudieran derivar. Los postulados de Smend habían tenido una difusión, reconocimiento y acogida considerables, había alcanzado un predicamento suficiente como para merecer ser pasada por el tamiz de un censor que, de modo sistemático, fuese sacando a relucir los argumentos y postulados que más problemáticos, polémicos o poco fundamentados. En tercer lugar, la réplica a Smend ofrecía a Kelsen la excusa perfecta para matizar aquellos de su propia teoría que, según su criterio, Smend había tergiversado o interpretado erróneamente ${ }^{14}$. Y, finalmente, en

${ }^{11}$ SMEND, R., Constitución y, cit., p. 39.

12 Ibídem, p. 48.

${ }^{13}$ Cfr. KELSEN, H., El Estado como integración. Una controversia de principio, ed. Tecnos, Madrid, 1997, p. 4. En especial la afirmación: "un autor del rango de Smend tiene el derecho a ser medido con su propia medida."

${ }^{14}$ Vid. KELSEN, H., El Estado como integración, cit., p. 4. En la que justifica la extensión de su análisis en "el fuerte efecto que la teoría de la integración ha desencadenado en el círculo de los especialistas" 
palabras de Kelsen, ese grado de detalle en su análisis, obedecería a "la peculiaridad de la exposición de Smend" a la que achaca el carecer de "una cierta inseguridad en la concepción” y, en definitiva, de ser poco “inteligible”"15.

\section{La cuestión metodológica}

A la hora de analizar la disquisición entre Kelsen y Smend se procederá siguiendo, en gran medida, la mecánica seguida por el propio Kelsen al realizar su crítica. De ahí que, antes de entrar a analizar la cuestión central de este trabajo, es decir, antes de ver el concepto de Estado como integración, se dedicarán unas líneas a distinguir la metodología y forma de enfocar el objeto de estudio seguidas por uno y otro. Esto resulta determinante para poder seguir la cadena de pensamientos que les ha llevado a formular sus respectivas propuestas, favorece el entendimiento de las conclusiones a las que llegan y proporciona ciertas claves que coadyuvan al descubrimiento y compresión de la coherencia interna del modelo científico del que se han valido.

Curiosamente, y a pesar de sus divergencias, ambos autores coinciden en señalar la inadecuación del método científico-causal como mecanismo mediante el que encauzar la realización de una teoría del Estado. Es decir, que los dos plantean sus teorías coincidiendo en la crítica hacia la que, en esos momentos, era la teoría del Estado dominante, de la cual, Georg Jellinek, era su máximo exponente ${ }^{16}$. Por consiguiente, "Smend se sitúa en el mismo frente, de igual raíz metodológica, que la Teoría Pura del Derecho en la lucha contra los equívocos a los que conduce la llamada teoría orgánica del Estado”17.

Sin embargo, pese a esa coincidencia en lo metódico de la que Kelsen habla, lo cierto es que Smend va a transitar por un camino diferente al de la Escuela de Viena, cuya visión positivista Smend considera necesario superar. Para ello acude a la ciencia del espíritu y toma a Theodor Litt como referente ${ }^{18}$. Esta ciencia del espíritu plantea que “individuo y comunidad no son realidades autónomas con un decurso propio, sino interdependientes y recíprocamente constitutivas” ${ }^{19}$. No obstante, y como Kelsen se encarga de señalar, en lo propugnado por Smend existen discrepancias. Principalmente porque, pese a que Smend no lo reconozca, sí toma en consideración aspectos de la teoría normativa de la Escuela de Viena, aspectos que tienen difícil -cuando no imposible- encaje con la ciencia del espíritu de Litt. Esto último es lo que permite a Kelsen dejar patente las contradicciones presentes en la obra de Smend respecto a este punto. "Smend, al querer

\footnotetext{
${ }^{15}$ KELSEN, H., El Estado como integración, cit., p. 5.

${ }^{16}$ La Teoría general del Estado de Georg Jellinek marcó el modo entender la Teoría del Estado a finales del siglo XIX y principios del XX. Para Jellinek "el Estado puede ser considerado desde un doble punto de vista: sociológico y jurídico, aunque el fundamento último del mismo es de carácter metajurídico, de manera que la positividad del derecho no se fundamenta en otra norma o principio del mismo ordenamiento, sino que descansa en la convicción de su obligatoriedad.” En DALLA VÍA, A. R., “Jellinek, Georg, Consideraciones sobre la Teoría general del Estado", en Cuestiones Constitucionales, Revista mexicana de Derecho constitucional, N 14, enero-junio, México D.F., 2006, p. 339.

${ }^{17}$ KELSEN, H., El Estado como integración, cit., p. 10.

${ }^{18}$ Theodor Litt, autor de Individuum und Gemeischaft obra en la que desarrolla su filosofía de la cultura y que sirve de fundamento para la ciencia del espíritu a la que Smend se acoge.

${ }^{19}$ GARCÍA AMADO, J. A., estudio preliminar en El Estado como integración. Una controversia de principio, ed. Tecnos, Madrid, 1997, p. XII.
} 
rechazar la teoría normativa del Estado de la Escuela de Viena y mantener, al mismo tiempo, la por él proclamada legalidad normativa del espíritu en general y del Estado en particular, se sienta al mismo tiempo en dos sillas, la Escuela de Viena y la filosofía de la cultura de Litt”"20.

En cuanto a la metodología de Kelsen, al modo en que lleva a efecto el estudio del Estado bastaría, casi, con hacer referencia al título de una de sus obras más conocidas, Teoría pura del Derecho ${ }^{21}$. Ese adjetivo, pura, es el mejor indicativo del método que Kelsen trata de aplicar. Lo que propugna -permítase la simplificación- es una forma de entender el estudio del Derecho desde un punto de vista exclusivamente jurídico, “a Kelsen lo que realmente le importaba era perfeccionar la metodología del estudio teórico del Derecho" ${ }^{22}$. En definitiva, "su concepción del método exclusivamente científico-jurídica es, sin embargo, expresión de un entendimiento de la interdisciplinariedad en régimen de división de trabajo, que debe conducir a una diferenciación metodológica de las ciencias y, de ese modo, respeta a las demás ciencias y sus métodos respectivos, sin integrarlas en el campo del Derecho"23. Consecuentemente con esa orientación normativa del método científico, Kelsen establecerá relaciones de imputación y realizará una abstracción de todas las cuestiones ajenas al propio derecho. Teniendo estas premisas en mente solo queda proceder a analizar la teoría del Estado de cada uno de ellos.

\section{LAS TEORÍAS DEL ESTADO EN BELIGERANCIA. ESPECIAL ATENCIÓN A LA TEORÍA DEL ESTADO COMO INTEGRACIÓN}

Condensar, en unas pocas páginas, los elementos basilares de las teorías del Estado de Kelsen y Smend resulta una tarea peliaguda, con un riesgo cierto de no representar con la debida fidelidad y rigor la profundidad y matices de sus postulados. No obstante, en las próximas líneas se esbozarán los principales elementos de ambas teorías para, posteriormente, proceder a poner de manifiesto los problemas que Kelsen achaca al Estado como integración formulado por Smend. La teoría de este último es el eje sobre el que se articula y gira este trabajo, en tanto son, precisamente, los diversos factores de integración en ella apuntados los que motivan e impulsan este artículo. Por este motivo, la teoría del Estado de Kelsen solo será aquí perfilada, apuntándose, únicamente, sus lineamientos principales, en la medida en que su conocimiento puede facilitar el entendimiento de algunas de las críticas apuntadas por el autor austrohúngaro.

\section{La teoría del Estado de Kelsen}

\section{A. La identidad entre Estado y Derecho}

\footnotetext{
${ }^{20}$ KELSEN, H., El Estado como integración, cit., p. 16.

${ }^{21}$ Aunque no debe olvidarse que su concepción del Estado tiene su reflejo en la obra, Teoría general del Estado y, no menos importante para una comprensión holística del sistema kelseniano, De la esencia y valor de la democracia, crucial para evitar interpretaciones sesgadas o parciales de sus postulados.

${ }^{22}$ RIVAYA, B., “Kelsen en España”, en Revista de Estudios Políticos (Nueva Época), No 107, EneroMarzo, Madrid, 2000, p.169.

${ }^{23}$ LEPSIUS, O., "El redescubrimiento de Weimar por parte de la doctrina del derecho político de la República Federal” en Historia Constitucional (revista electrónica), № 9, 2008, p. 6. Puede consultarse en: http://www.historiaconstitucional.com/index.php/historiaconstitucional/article/view/152
} 
En una reducción excesiva (por simplificadora) podría condensarse la teoría del Estado de Kelsen en la identificación entre Estado y Derecho. Sin embargo, detrás de esa aseveración hay toda una cadena de pensamientos que vale la pena traer a colación, así como las consecuencias que esa identificación supone.

Para comprender las aportaciones de Kelsen y, sobre todo, para apreciar, en sus justos términos, el salto cualitativo que supone respecto a la teoría dominante de la época, resulta necesario delinear, aunque sea de manera necesariamente sucinta, las características del pensamiento de orientación causal que Kelsen, con su enfoque normativo, trata de superar.

La teoría de orientación casual concibe al Estado y al Derecho como instituciones diferentes, aunque íntimamente relacionadas. Así, para Max Webber, a quien puede identificarse como perteneciente a esta tendencia, "por Estado debe entenderse un instituto político de actividad continuada, cuando y en la medida en que su cuadro administrativo mantenga con éxito la pretensión al monopolio legítimo de la coacción física para el mantenimiento del orden vigente" ${ }^{24}$. ¿Y cuál es el papel del Derecho? El Derecho es concebido como un conjunto de normas, normas que "constituyen un orden garantizado por la constelación de hechos que determinan al Estado, como una situación de carácter real”25, por tanto, existe conexión pero no identificación entre Estado y Derecho.

Frente a esa visión dual, Kelsen lleva a cabo una interiorización de la coacción en la norma jurídica ${ }^{26}$. Esto supone que el derecho deja de ser un conjunto de normas cuyo cumplimiento venga asegurado por la existencia de un poder coactivo externo. Al interiorizar la coacción, la norma ya no tendrá carácter imperativo sino condicional, esto es, solo en aquellas situaciones y bajo las circunstancias que vengan explicitadas por la norma se podrá ejercer la coacción. La concepción kelseniana del Derecho establece las coordenadas que servirían "para legitimar cualquier sistema político. [...] la potencia de su pensamiento reside precisamente en su capacidad para terminar de demoler el positivismo jurídico del siglo XIX”27. Por lo tanto, no solo apunta a la teoría de orientación causal dominante, sino que reformula y renueva la concepción positivista precedente.

Pero, ¿cómo se proyectan tales posiciones dogmáticas sobre el concepto de Estado? Al concebir el Derecho como conjunto de normas de carácter coactivo, entonces, "si el Estado es un cuadro coactivo (...), y tomando en cuenta que el cuadro coactivo del

${ }^{24}$ WEBER, M., Economía y sociedad, Fondo de cultura Económica de España, S.L., Madrid, edición de 2002, pp. 43-44.

${ }^{25}$ SCHMILL ORDÓÑEZ, U., "La Teoría de la Identidad del Derecho y del Estado de Hans Kelsen” en La Reforma del Estado. Estudios Comparados, editado por José Luis Soberanes, Diego Valadéz y Hugo A. Concha, Universidad Nacional Autónoma de México y Dirección General de Asuntos Jurídicos de la Presidencia de la República, México D.F., 1996, p. 590.

${ }^{26}$ Cfr. SCHMILL ORDÓÑEZ, U., en la introducción a Problemas capitales de la Teoría jurídica del Estado, ed. Porrúa, S. A., México, 1987, p. XVII.

${ }^{27}$ DE MIGUEL BÁRCENA, J. y TAJADURA TEJADA, J., Kelsen versus Schmitt, cit., p. 86. 
Estado posee un orden con base en el cual es posible hacer la imputación de ciertos actos a su unidad, ergo el Estado es idéntico al derecho" ${ }^{28}$.

De esta afirmación se entresacan dos ideas importantes, de una parte, que el Estado es entendido como un centro de imputación de determinados actos: los explicitados por el orden jurídico vigente ${ }^{29}$. Y de otra, que hay una identificación total entre Derecho y Estado. Las consecuencias de esta identidad se proyectan tanto sobre lo que haya de entenderse por Estado como sobre los elementos constitutivos del mismo.

Entendidas de este modo, la Teoría General del Estado y la Teoría Jurídica pasan a ser una, en la medida que los problemas que pudieran plantearse respecto al concepto de Estado se podrían resolver desde las posiciones de la Teoría Jurídica pues, en última instancia, se trataría de cuestiones jurídicas. Por otra parte, en lo que respecta a los, así considerados por Georg Jellinek, como elementos del Estado, esto es, el territorio (elemento material), la población (elemento sustancial), y el gobierno o poder (elemento formal), se va a producir un cambio sustancial. Estos, según la visión Kelseniana del Estado "no son más que la vigencia en sí del orden jurídico y los campos espacial y personal de éstas, respectivamente” ${ }^{30}$.

Por consiguiente, a la hora de conocer las características de esos elementos en cualquier estado, bastará acudir a su ordenamiento jurídico, pues allí se residenciarán y estarán definidos. En definitiva, será territorio del Estado el que el ordenamiento defina como tal, y otro tanto puede proclamarse respecto a su población, que estará constituida por aquellos que reúnan los requisitos prescritos por la normativa correspondiente. Incluso es aplicable respecto del poder, al ser Derecho de cada estado concreto el que defina las instituciones que están legitimadas para ostentarlo y el modo en que habrán de ejercerlo.

\section{B. Consecuencias para el concepto de Constitución}

Considerar al Estado como un ordenamiento jurídico lleva a que la existencia del mismo esté condicionada a la de ese conjunto de previsiones normativas ordenadas y sistematizadas que lo articule. No habrá Estado sin Derecho. En esta concepción jurídica del Estado no debe extrañar que se entienda a la Constitución como una norma jurídica, concretamente la norma jerárquica superior, parámetro de validez de las previsiones normativas de rango inferior. En definitiva, para Kelsen, la Constitución es norma jurídica. Como se apuntará, este será uno de los puntos de discrepancia con Smend.

\section{El Estado como integración}

\section{A. Características generales de la teoría de Smend}

${ }^{28}$ SCHMILL ORDÓÑEZ, U., "La Teoría de la Identidad...” cit., p. 594.

${ }^{29}$ KELSEN, H., Compendio de la Teoría general del Estado, ed. Colofón, S.A., México D.F., 2007, pp. 116-117.

30 Ibídem, pp. 130-131. 
Smend plantea su teoría del Estado partiendo de la crítica a los tres elementos que la teoría clásica venía apuntado (territorio ${ }^{31}$, población y poder). Les achaca su inadecuación como punto de partida, pues se pierden "en una concepción espacialista y estática” ${ }^{32}$. La concepción de Smend es dinámica, de ahí que rechace tomar al individuo de forma aislada como referencia, para él, de un solo sujeto difícilmente se puede derivar la dinámica del conjunto, de la sociedad. La participación del individuo en la sociedad viene propiciada y provocada por la propia comunidad. Es la sociedad la que, con sus dinámicas, moviliza y canaliza la voluntad del individuo. De este modo, Smend está realizando una inversión de la, preponderante, concepción de la sociedad como derivación mecánica del individuo $^{33}$. Como alternativa para esclarecer la estructura de la realidad socio-cultural, él plantea un modelo en el que el individuo puede realizarse, modelo que, por el influjo de Theodor Litt, va a definir como "un sistema de influencias mutuas, o (...) como flujo circular"34.

"Pese a la abstracción de sus planteamientos, el discurso científico se situaba con Smend en un plano eminentemente pragmático, donde los receptores principales eran los dirigentes, magistrados y burócratas y el objetivo perseguido era contribuir a que los ciudadanos se reconociesen en sus instituciones jurídico-públicas" 35 . Smend concibe al Estado como "un ámbito parcial de la realidad espiritual" ${ }^{36}$. Su concepto de Estado tiene en cuenta la realidad social (una de las carencias que Smend achaca a la teoría kelseniana del Estado).

De este modo, la existencia del Estado viene condicionada por la preexistencia de una realidad social en la que los individuos sienten que forman parte de esa colectividad. Colectividad que, en tanto que es dinámica, no puede verse constreñida por el orden jurídico, al que considera un factor de carácter estático. En definitiva, para Smend, el Estado es "una realización cultural que como tal realidad de la vida del espíritu es fluida, necesita continuamente de renovación y desarrollo"37. Esto le permite justificar la existencia de una conciencia colectiva de pertenencia al Estado, conciencia de la que participarían incluso quienes generalmente no participan en el ámbito social del Estado. Las justificaciones para sustentar esta postura son variadas y se focalizan en cada tipo de sujeto o grupo social respecto del cual se pudiera cuestionar su participación en la colectividad.

Analizando los distintos colectivos cuya participación de la conciencia colectiva es susceptible de ser cuestionada su vemos que, respecto de la, por el denominada, "masa inánime”38. Hace distinción, entre aquellos que en algún momento han participado

${ }^{31}$ Smend concibe el territorio como un contenido espiritual integrador señalando que, probablemente, sea el elemento más importante para la comunidad política. Cfr. SMEND, R., Constitución... cit., p. 103.

32 SMEND, R., Constitución y, cit., p. 52.

${ }^{33}$ Cfr. ibídem, p. 54.

34 Ibídem, p. 55.

35 MARTÍN, S. “Autoconservación contra nación. Lecturas de la Integrationslehre de Rudolf Smend en la doctrina jurídico-política española de los años treinta”, en Revista de Estudios Políticos, No 182, 2018, p. 103.

36 SMEND, R., Constitución y, cit., p. 56.

37 Ibídem, p. 61.

38 Término con el que define a todos aquellos que, al menos en principio y en apariencia no participan de la vida política, bien por incapacidad o por propia voluntad de abstención. 
existencialmente del Estado (por ejemplo, en la guerra), pues en ellos ya existe esa conciencia, al haberse formado un vínculo entre la persona y la sociedad. Por lo que respecta a los que a los niños o personas con algún tipo de afectación mental, afirma la su pertenencia a la comunidad, basándose en la existencia de una intencionalidad latente, potencial, de pertenecer a la comunidad. Desde un punto de vista práctico, se puede decir que todos los ciudadanos tienen ese sentimiento de pertenencia al Estado, salvo aquellos que renuncien a pertenecer a él.

Con lo hasta ahora referido se han sentado las bases a partir de las cuáles resultará más sencillo el comprender la gran aportación de Smend a la teoría del Estado, su teoría de la integración. Para la elaboración de esta teoría parte de concebir al Estado como realidad espiritual y dinámica, en continua renovación y cambio. A ese proceso, es al que denomina integración ${ }^{39}$. La integración será la base desde la cual construirá su teoría del Estado. Smend va a definir tres tipos de integración, aunque él mismo puntualiza que no debe tomarse como una teoría acabada, sino como "un primer esbozo, necesariamente provisional. Especialmente el esquema tripartito" 40 . En todo caso, debe advertirse que los elementos de integración (personal, funcional o procesual y material u objetiva) no han de verse como compartimentos estancos, sino como factores interrelacionados.

\section{B. La integración personal}

La integración personal es identificada por Smend con el caudillaje, si bien es cierto que realiza una matización importante respecto de la idea que debe de tenerse de caudillo. Puntualizando y enriqueciendo las visiones en que se concibe a esa figura solamente como alguien encargado de llevar a cabo las misiones de gobierno de un modo más eficiente. Junto a la realización de las tareas propias del gobierno añade otras. Así, el gobernante/caudillo tendría que ganarse esa posición de primacía respecto a aquellos a los que gobierna. Ilustra esta afirmación a través de ejemplos, incluyendo tanto formas de gobierno parlamentarias como monárquicas. En el caso de la forma de gobierno parlamentaria correspondería al gabinete el mantener la mayoría parlamentaria y después por medio de la integración funcional- integrar al conjunto de los ciudadanos, conformándose así una unidad política.

Sin embargo, es en la monarquía donde se refleja, de un modo más nítido, esa integración personal que Smend postula. Los motivos argüidos por el autor giran en torno a una serie de imponderables que van más allá de la eficacia en la gestión de sus funciones por parte de quien ostente la corona en cada momento. Siguiendo este razonamiento, la continuidad o rechazo de la monarquía no vendrían fundadas solo por las capacidades técnicas del rey o reina en cuestión, sino que habría de incluir toda una serie de atribuciones que no son de carácter técnico y que, sin embargo, resultarían fundamentales a la hora de valorar la capacidad integradora de la forma de estado monárquica. Esos factores adicionales serían, la representación de la continuidad y la encarnación de la unidad política del pueblo.

\footnotetext{
${ }^{39}$ Cfr. SMEND, R., Constitución y, cit., p. 63.

${ }^{40}$ Ibídem, p. 69.
} 
En definitiva, junto a las funciones que pueda realizar como gobernante, el monarca, debe también ser medido por otras variables, concretamente por la capacidad para operar como símbolo de unidad, de tradición, de permanencia de unos valores que son comunes a la sociedad y con los que esta se siente identificada. Resulta especialmente gráfica la afirmación que realiza Smend, tomando a Hugo Preuss como referencia, cuando señala: "cuando se ovaciona al soberano no se pretende con ello honrar a una persona concreta, sino que se trata más bien de un acto de autoconciencia de un pueblo políticamente unido" ${ }^{41}$. Lo relevante, por tanto, es constatar si el monarca mueva a la sociedad, si genera en ella un sentimiento de acatamiento, de pertenencia. Para Smend esta función de integración resulta crucial, lo que se constata en la preferencia de lo simbólico sobre lo técnico, en la capacidad de adhesión frente a la de gestión. Esta preferencia no solo se predica para el monarca, también es el motivo que le lleve a situar en un plano preeminente a los funcionarios políticos sobre los burocráticos, por anteponer los primeros la labor integradora a la técnica ${ }^{42}$.

Comunidad política, por su parte, posee una naturaleza integradora que se predica tanto ad intra, esto es respecto del pueblo del Estado, como en lo referente "a la política exterior, a las relaciones con otros países” ${ }^{43}$. El nexo de unión entre las dos esferas vendría ejercido por los que Smend denomina "hombres de Estado". Estos representan una determinada política, una que se les puede exigir y, a la vez, es la que cabe esperar que lleven a efecto. La fuerza de la identificación existente entre persona y política por ella ejercida es de tal magnitud que cualquier modificación de la política ejercida, debe suponer, inexorablemente, un cambio en la persona. Lo que subyace detrás de esta afirmación, al igual que en su visión del monarca como símbolo, es la existencia de una conexión entre la integración personal y la integración material -que se analizará más adelante-. Como se ha avanzado, las formas de integración están interconectadas.

\section{Integración funcional o procesal}

La integración funcional vendría representada por las formas de vivir que tienden a crear un sentido colectivo. "Procesos que tienden a producir una síntesis social, esto es que tienden, bien a que el contenido espiritual se haga comunitario, o bien a reforzar la vivencia comunitaria de la vida social" 44 . Los ejemplos de esta forma de integración son múltiples y de amplio espectro. Abarcarían desde las marchas militares a la celebración de elecciones. Todos son configurados como ritos que permiten cohesionar a la sociedad y, a la vez, generar un sentimiento de pertenencia, de grupo.

Para Smend, el uso que el fascismo realiza de las paradas militares es un ejemplo paradigmático de esta función integradora ${ }^{45}$. Sin embargo, a día de hoy quizá resulte más interesante la inclusión de las elecciones y votaciones como forma de integración, en la medida en que son procesos de conformación de la voluntad comunitaria que suponen una

\footnotetext{
41 Ibidem, p. 74.

${ }^{42}$ Cfr. ibídem, p.76.

43 Ibidem, p. 76.

44 Ibidem, p. 78.

45 En ese momento era el fascismo italiano, aunque no pasarían muchos años hasta que el nazismo reforzara su poder, con medios similares, en Alemania.
} 
reafirmación y restauración de la comunidad política ${ }^{46}$. Es decir, configura a las elecciones y votaciones como un modo constante de renovación de los vínculos de la sociedad y, como tales, no pueden ser entendidas como un negocio jurídico. Lo que caracterizará a las elecciones - pero también a las actuaciones parlamentarias, a la formación de gobiernos, a los referéndums- será que todos son procesos espirituales de integración colectiva. Individualizan a cada pueblo, fundamentan su estructura política y generan un acervo común que, periódicamente, se ve reafirmado.

Una vez más, vuelve a repetirse la idea, en la que ya se había ahondado al hablar de la integración personal, de que lo relevante no es tanto la labor que, por ejemplo, el parlamento pueda realizar sino su capacidad para crear, tanto "en el Parlamento, como fuera de él, una auténtica comunidad política, una unión de voluntades, una actitud política general determinada" ${ }^{47}$. Para ello será fundamental que esa fuerza integradora, que debe emanar de sus actos, sea capaz de aglutinar a toda la comunidad.

Finalmente, destacar, que la integración formal no existiría sin una comunidad de valores y, al mismo tiempo, tampoco es posible la integración por medio de valores sustantivos en ausencia de los funcionales. Lo que existe en la realidad son situaciones en las que predomina uno u otro, pero sin excluirse mutuamente, pues existe vinculación entre ellos. Conexión que llega al punto de poder considerarse como las dos caras de una misma moneda pero, en todo caso, deben distinguirse unos elementos de otros ${ }^{48}$.

\section{La integración material}

Este tipo de integración se concreta y canaliza mediante la participación en un contenido sustantivo. Existen una serie de elementos materiales que poseen eficacia integradora, símbolos que representan valores históricos, culturales. Si están institucionalizados, esto es, si tienen vigencia como símbolos políticos de la comunidad, contribuirán a la identificación de la sociedad con ellos. Tan importante como su institucionalización, es que esos símbolos estén revestidos de un valor que se haya ido afianzando con el paso del tiempo, que se haya forjado un vínculo con ellos por parte de la colectividad. Es decir, ha de tratarse de símbolos con los que la sociedad se sienta representada, elementos capaces generar adhesión o que, al menos, permitan hacer reverberar en la subconsciente colectivo momentos o situaciones de unión y fuerza de la comunidad. Smend identifica algunos de ellos: las banderas, los escudos, los Jefes de Estado (aunque señalando que cumplen mejor esta función los monarcas), las ceremonias políticas y las fiestas nacionales ${ }^{49}$.

Estos elementos simbólicos enardecen las emociones y generan sentimientos colectivos, en parte por su naturaleza irracional, pero, sobre todo, porque "el símbolo

${ }^{46}$ Esta visión de las elecciones puede contribuir a explicar el por qué las elecciones al Parlamento Europeo tienen tan baja participación. Al no existir una noción tan fuerte de comunidad en dicho ámbito, interés por participar y reforzar el vínculo no es sentido por los ciudadanos del mismo modo que en las elecciones estatales u autonómicas.

${ }^{47}$ SMEND, R., Constitución y, cit., p. 86.

${ }^{48}$ Cfr. ibidem, p. 93.

${ }^{49}$ Cfr. ibidem, p. 97. 
siempre es más moldeable que las formulaciones racionales y legales” ${ }^{50}$, al poder ser sentido sin los condicionamientos de aquellas. ¿Qué aportaciones hace la existencia de estos símbolos? ¿A qué contribuyen en la configuración del Estado? Su función debe enmarcarse en la creación de un sentimiento patriótico, al menos esa es la idea que se desprende de las palabras de Smend, cuando señala a esta forma de integración como estratégica para "lograr hoy en día el máximo grado de compromiso e integración en el Estado”.

Finalmente, debe indicarse que estos símbolos no son estáticos (si bien es cierto que han de contar con una cierta significancia sustentada en un bagaje histórico) porque, en tanto la naturaleza del Estado es dinámica, los fines que ese Estado persigue van cambiando, lo que, consecuentemente, se traslada a los símbolos y los hace susceptibles de cambio y adaptación a las nuevas realidades colectivas. Ese carácter evolutivo les llevará a que, en cada momento histórico, ocuparán un lugar destacado aquellos símbolos que mejor sirvan a los intereses de la sociedad, que mejor contribuyan a mantenerla unida. Incluso aunque ello suponga la sustitución de antiguas referencias por otras nuevas, más acordes con la función que se persigue.

\section{E. Consecuencias de la teoría de la integración para el concepto de Constitución}

Vistas, aunque sea de un modo necesariamente sucinto, las características de la teoría de la integración, procede analizar su influencia en la concepción del Estado y, también, en la de constitución. A modo de resumen, puede decirse que la teoría de la integración concibe al Estado como "una unidad individual, una totalidad que se halla determinada por la concreción de valores sustantivos en situaciones históricas determinadas" 51 . Por lo que respecta al concepto de Constitución, esta será "la plasmación legal o normativa de aspectos determinados de este proceso, (se refiere al proceso de integración)" 52 . Sin embargo, para Smend, la Constitución no se circunscribe a aquello que su texto señala, es decir, no puede "ser concebida como simple norma positiva porque el Estado no una pura forma jurídica ni el resumen estático de los tres elementos (territorio, pueblo y poder) sino vida espiritual" ${ }^{53}$. No obstante, la plasmación que se dé en la Constitución a los elementos básicos de la integración (incluidas cuestiones como los colores de la bandera o el himno) sí será crucial; pero siempre teniendo en cuenta que los elementos de integración no son algo estático sino dinámico, con lo que la letra de la Constitución podría no reflejar la realidad si esos elementos cambian y ella no lo refleja. Con la pérdida de fuerza adhesiva que el texto constitucional pudiera sufrir a raíz de dichas disonancias.

Acaso de manera inconsciente, Smend está enunciando el sustrato que subyace a las mutaciones constitucionales. Sin embargo, él lo plantea de un modo tal que hace ver que, si esa modificación de los elementos de integración tiene lugar, lo que diga la letra de

\footnotetext{
${ }^{50}$ Ibidem, p. 98.

51 Ibidem, p. 95.

52 Ibidem, p. 132.

53 SOSA WAGNER, F., Maestros alemanes del Derecho público (II), Marcial Pons, Madrid, 2004, p.
} 263. 
la Constitución va a importar poco. Por ello no resulta extraño que sitúe la regulación de los derechos humanos, los preámbulos, el territorio del Estado, la forma política y el pabellón nacional como "los elementos que, en lo fundamental, configuran la esencia y la realidad del Estado" 54 .

\section{Las críticas de Kelsen a la teoría de la integración}

Smend, en Constitución y Derecho constitucional realiza, como se ha advertido, una crítica al pensamiento de Kelsen. Tal es el cariz de la obra de Smend que lleva a Kelsen a dedicar un escrito de la magnitud de El Estado como integración. Una controversia de principio a responderle. En esa obra, además de dar réplica a las palabras de Smend y sacar a la luz las deficiencias de la teoría propuesta por éste, Kelsen aprovecha para matizar y afianzar su propia teoría del Estado. A lo largo de El Estado como integración. Una controversia de principio se puede ver cómo va dando respuesta a las diferentes carencias que Smend le achaca a su teoría. Como ya se ha indicado, las divergencias comienzan incluso en cuanto a la metodología empleada ya que, si bien es cierto que ambos coinciden en su rechazo de los tres elementos del Estado propugnados por la teoría de Georg Jellinek, no es menos cierto que ahí terminan sus coincidencias ${ }^{55}$. Los focos de conflicto, sin embargo, son numerosos.

En primero lugar, al reproche de que la Escuela de Viena no acuda a la ciencia del espíritu. Kelsen replica que la teoría del Estado por él propuesta sí se plantea como ciencia del espíritu; si bien reconoce que el concepto de espíritu que manejan difiere del utilizado por Smend ${ }^{56}$.

En segundo lugar, en lo atinente a la cuestión metodológica, resulta muy interesante el comprobar cómo, a decir de Kelsen, Smend se vale de muchos postulados de la Escuela de Viena, de hecho, le resulta cuando menos sorprendente que, si para Smend los sistemas sociales son normativos y la legalidad del Estado también lo es no llegue a las conclusiones que la Escuela de Viena alcanza. Las razones a las que Kelsen achaca estas divergencias son: de una parte, que Smend ha tergiversado y malinterpretado algunas de las proposiciones de la Escuela de Viena. Y, de otra, que ha hecho un híbrido entre la Escuela de Viena y lo propuesto por Theodor Litt; esto justificaría la afirmación, antes apuntada, en la que acusa a Smend de sentarse en dos sillas. Consecuencia de todo lo referido es que la teoría de Smend resulta engañosa y confusa, al extremo de llegar a admitir la existencia de lo natural cuando él era un adalid de la concepción espiritual.

En tercer lugar, surge una crítica que resulta difícil de comprender, el hecho de que Kelsen no tenga en cuenta la realidad social; resulta cuanto menos sorprendente, sobre todo si se toma en consideración que estamos hablando del ideólogo del Tribunal Constitucional. Es cierto que en su teoría lo deja al margen, pero es que aquí está llevando a cabo un análisis empírico de una materia concreta, el Derecho, ello no significa que niegue todo lo

54 Ibidem, p. 168.

55 Resulta interesante hasta qué punto coinciden en esa crítica que el propio Smend se remite a la crítica que la Escuela de Viena hace a esa teoría. Vid. SMEND, R., Constitución y, cit., p. 105.

${ }^{56}$ Cfr. KELSEN, H., El Estado como integración, cit., p. 13 y p. 17. 
demás, simplemente no entran en su campo de estudio. Esto no debe llevar a suponer que no sea consciente de que la concurrencia de otras variables. Al contrario, tiene que ser muy consciente de su existencia, pues solo sabiendo que existen puede apartarse de ellas y evitar que contaminen su objeto de estudio. Desde un punto de vista científico la labor de Kelsen debe considerarse impecable, más allá de lo acertadas que puedan ser sus conclusiones o la elección de los elementos que deberían conformar su campo de estudio. Si bien es cierto que, al centrarse en un aspecto tan concreto quizá sus conclusiones deberían ser complementadas con otras teorías o, al menos, esa es la sensación que produce en quien esto escribe.

En cuarto lugar, aunque relacionado con lo anterior, no puede dejar de hacerse referencia al hecho de que, en la teoría del Estado de Kelsen, se rechaza la existencia de "una realidad del Estado previa o distinta de la de un ordenamiento jurídico" ${ }^{57}$. Lo anterior implica que, en la medida en que no haya un ordenamiento jurídico que regule su existencia, no puede hablarse del Estado como realidad. Esto contrasta con la visión prejurídica del Estado que tiene Smend, manifestada en ese sentimiento colectivo de formar parte de una comunidad. Sentimiento que se sustenta en los elementos de integración mencionados. En definitiva, la postura de Smend supone el rechazo a la equiparación entre Estado y Derecho que Kelsen propugna, al encubrir "formas de poder orgánicas y supraempíricas ajenas al pensamiento científico"58.

Finalmente, en lo referente al concepto de Constitución, las divergencias resultan evidentes, y derivan o provocan (según el caso) las diferencias en la noción de Estado. Mientras la concepción kelseniana caracteriza a la Constitución como norma jerárquicamente superior dentro de las que componen el ordenamiento jurídico y parámetro de validez de las inferiores. La postura de Smend diseña una Constitución que es fruto del proceso de integración y, a la vez, medio y vehículo para mantener a la comunidad integrada y unida. Lo que le lleva a afirmar que, si se viera a la Constitución solamente en cuanto que norma jurídica, ésta "carecería de cualquier relevancia y significado, sería letra muerta" 59 .

Para concluir el análisis de los puntos de controversia debe señalarse que, buscando ambos pensadores el formular una teoría libre de condicionantes, al final llegan a una situación en la que, a los ojos del otro, ambos han incumplido este propósito. Como apunta GARCÍA AMADO, "Smend ve en Kelsen el representante de una política liberal tachada de disolvente del Estado y desconfiada frente a lo colectivo. (Y) Kelsen tilda a Smend de defensor de un pensamiento conservador que sustancializa el Estado y quiere en el fondo combatir el Estado de derecho representado por la constitución de Weimar”60.

\section{CONCLUSIONES DE LA CONTROVERSIA Y REFLEXIONES SOBRE LA REALIDAD ACTUAL}

\footnotetext{
${ }^{57}$ GARCÍA AMADO, J. A., estudio preliminar en El estado, cit., p. X.

${ }^{58}$ DE MIGUEL BÁRCENA, J. y TAJADURA TEJADA, J., Kelsen versus Schmitt, cit., p. 84.

${ }^{59}$ GARCÍA AMADO, J. A., estudio preliminar en El estado, cit., p. X.

60 Ibidem, p. XXII.
} 
Una vez expuesta la controversia, al menos en sus líneas generales, cabe realizar algunas reflexiones sobre la misma. En primer lugar, y compartiendo algunos elementos esenciales de ambas teorías y discrepando en otros, lo cierto es que la postura de Kelsen en lo que se refiere a la idea de que sin ordenamiento jurídico no se puede hablar de Estado, es más acorde con la realidad imperante. Si se quiere, a efectos nominativos, podrá hablarse de Estado, aunque no haya ordenamiento jurídico pero, en puridad, no lo será. No lo será porque la existencia de un ordenamiento jurídico supone contar con ciertas garantías y seguridad que vendrán a asegurar la existencia de esa comunidad política organizada. El Estado o es Derecho o no es Estado. La postura de Smend, en la que plantea una existencia prejurídica del Estado tropieza con la realidad. Por supuesto, el sentimiento de comunidad no debe desdeñarse; como idea romántica, funciona muy bien, pero el sustrato preexistente, hasta que no se organice política y jurídicamente, hasta que no tenga plasmación positiva, y se determine cuáles de esos elementos anteriores tienen cabida -y de qué modo-, no son realidad estatal, sencillamente porque no hay Estado.

Por otra parte, una vez configurado el Estado, la propuesta de Smend referente a tomar en consideración los cambios que se producen en la sociedad y que pueden hacer que la Constitución sea letra muerta resulta más que oportuna. Se suele decir que el Derecho va por detrás de la sociedad y, generalmente, es cierto. No obstante, en tanto esos cambios no sean recogidos en normas o aplicados como criterio de interpretación por los tribunales, difícilmente se pueden ver satisfechos o, al menos, amparados por la protección y seguridad que el Derecho, con su fuerza coactiva, proporciona. Ahora bien, la influencia de la sociedad en la evolución del Derecho es innegable y debe ser tomada en consideración por los tribunales, especialmente, por los tribunales constitucionales.

En definitiva, ambos autores aportan apreciaciones y matices que son de gran utilidad para la comprensión del Estado, pues los Estados actuales contienen rasgos de ambas teorías, que primen los aspectos de una u otra dependerá más del momento histórico que ese Estado viva, así como de las propias necesidades y problemas a los que deba hacer frente. Este es el aspecto más valioso de las teorías aquí presentadas a la hora de afrontar los problemas que España afronta en la actualidad, en los que algunos de los elementos de integración están fallando o ya han fallado. Seguramente porque se han producido ciertas confusiones o porque no se tenía claro a dónde llegar. Quizá se ha confundido integración con asimilación y, probablemente, no se tenía claro ni cuánto, ni qué integrar. En lugar de diseñarse un modelo capaz de generar dinámicas integradoras, se ha procedido a la implementación de un modelo tendente a la asimilación difuminadora de la diferencia, fundada en un mal modo de entender la igualdad, que, en última instancia, ha actuado como fuerza disolvente.

Aunque el Derecho sea el pilar en torno al que se construye y aglutina la vida en sociedad, no pueden desdeñarse las carencias existentes a la hora de construir una idea de España como estado capaz de aglutinar las voluntades de cuantos en él conviven. De ahí que resulte crucial analizar qué elementos de integración han fallado, potenciar aquellos que contribuyan a mantener su cohesión y, sobre todo, buscar nuevos elementos de integración, también en lo jurídico. 
La inveterada vertebración de España ${ }^{61}$, es un proyecto demasiado difícil como para prescindir de mecanismos y fórmulas que pudieran contribuir a su realización. Una "reforma territorial en el plano de lo simbólico" ${ }^{62}$, como la que agudamente propone MORENO GONZALEZ ${ }^{63}$, se antoja ineludible. El valor de lo simbólico, los intangibles hilos que entrelazan y conectan a la comunidad, son demasiado importantes como para no ser considerados por el ordenamiento. Desde lo jurídico se debe buscar el modo de reflejarlos, reforzarlos y potenciarlos allí donde sea oportuno, y cambiarlos para que lo que, en su momento pudo ser un factor de integración, no se convierta en elemento de discordia y enfrentamiento. El acomodo de las diferentes realidades que conforman España no debe pasar por la imposición desde lo jurídico, sino desde el reconocimiento y generación de un marco de convivencia que posea una capacidad integradora de la que el actual parece andar escaso. Y esto solo puede lograrse a través de la reforma constitucional.

\section{BIBLIOGRAFÍA}

- $\quad$ CASQUETE, J. y TAJADURA, J., La Constitución de Weimar: Historia, política y derecho, Centro de Estudios Políticos y Constitucionales, Madrid, 2020.

- $\quad$ DALLA VÍA, A. R., “Jellinek, Georg, Consideraciones sobre la Teoría general del Estado”, en Cuestiones Constitucionales, Revista mexicana de Derecho constitucional, $\mathrm{N}^{\circ}$ 14, enero-junio, México D.F., 2006.

- $\quad$ DE MIGUEL BÁRCENA, J. y TAJADURA TEJADA, J., Kelsen versus Schmitt. Política y derecho en la crisis del constitucionalismo, Guillermo Escolar editor, Madrid, 2018.

- $\quad$ GARCÍA AMADO, J. A., estudio preliminar en El Estado como integración. Una controversia de principio, ed. Tecnos, Madrid, 1997.

- $\quad$ KELSEN, H., Compendio de la Teoría general del Estado, ed. Colofón, S.A., México D.F., 2007.

- $\quad$ KELSEN, H., El Estado como integración. Una controversia de principio, ed. Tecnos, Madrid, 1997.

- $\quad$ LEPSIUS, O., "El redescubrimiento de Weimar por parte de la doctrina del derecho político de la República Federal” en Historia Constitucional (revista electrónica), N 9, 2008.

Enlace:

http://www.historiaconstitucional.com/index.php/historiaconstitucional/article/view/152

${ }^{61}$ ORTEGA Y GASSET, J., España invertebrada, Espasa, Barcelona 2010.

${ }^{62}$ MORENO GONZÁLEZ, G., "España, cuestión de integración constitucional”, en ESTUPIÑÁN ACHURY, L., MORENO GONZÁLEZ, G. y MONTIEL MÁRQUEZ, A. (Coords.). La cuestión territorial a debate: España y Colombia, Universidad Libre, Bogotá, pp. 81-103, especialmente, pp. 94 y ss.

${ }^{63}$ El modelo propuesto por MORENO GONZÁLEZ, entre otros elementos, apuesta por considerar factores como la equidad territorial, así como integrar la enorme y rica diversidad cultural de España, un factor que, para el autor de estas líneas, se antoja crucial y cuya importancia rara vez se toma en consideración. 
- $\quad$ LUCAS VERDÚ, P. L., La lucha contra el positivismo jurídico en la República de Weimar, Ed. Tecnos, Madrid, 1987.

- $\quad$ MARTÍN, S. “Autoconservación contra nación. Lecturas de la Integrationslehre de Rudolf Smend en la doctrina jurídico-política española de los años treinta”, en Revista de Estudios Políticos, No 182, 2018, pp. 99-128.

- MORENO GONZÁLEZ, G., “España, cuestión de integración constitucional”, en ESTUPIÑÁN ACHURY, L., MORENO GONZÁLEZ, G. y MONTIEL MÁRQUEZ, A. (Coords.). La cuestión territorial a debate: España y Colombia, Universidad Libre, Bogotá, pp. 81-103.

- $\quad$ ORTEGA Y GASSET, J., España invertebrada, Espasa, Barcelona 2010.

- $\quad$ RIVAYA, B., “Kelsen en España”, en Revista de Estudios Políticos, N 107, EneroMarzo, Madrid, 2000.

- $\quad$ SCHMILL ORDÓÑEZ, U., "La Teoría de la Identidad del Derecho y del Estado de Hans Kelsen” en La Reforma del Estado. Estudios Comparados, editado por José Luis Soberanes, Diego Valadéz y Hugo A. Concha, Universidad Nacional Autónoma de México y Dirección General de Asuntos Jurídicos de la Presidencia de la República, México D.F, 1996.

- $\quad$ SCHMILL ORDÓÑEZ, U., "Introducción”, en Kensel, Hans. Problemas capitales de la Teoría jurídica del Estado, desarrollados con base en la doctrina de la proposición jurídica, ed. Porrúa, S. A., México, 1987.

- SMEND, R., Constitución y derecho constitucional, Centro de Estudios Constitucionales, Madrid, 1985.

- $\quad$ SMEND, R. y KELSEN, H., La controversia Smend/Kelsen sobre la integración en la Constitución de Weimar: Constitución y Derecho Constitucional versus El Estado como integración, Tecnos, Madrid, 2019

- $\quad$ SOSA WAGNER, F., Maestros alemanes del Derecho público (II), Marcial Pons, Madrid y Barcelona, 2004.

- Weber, M., Economía y sociedad, Fondo de cultura Económica de España, S.L., Madrid, edición de 2002. 